\title{
Correspondence
}

The role of nurses at tribunals

Sir: Sir John Wood (1998), in his article about his expectations of the psychiatrists at tribunal hearings, almost mentioned the role of the nurse when he noted it was advisable to ask "the professional staff to outline the programme that has been evolved to assist the patient's general recovery". Almost, but not quite.

This was an article about psychiatrists but I think very few of these would say they do not rely on nursing staff to offer the main picture of day-to-day behaviour in the ward as well as information about persisting or reducing signs of any psychiatric condition. In theory, it is only the responsible medical officer and the social worker who are expected to attend the tribunal and sometimes one finds that nurses think they cannot or should not do so. They have even sat outside waiting for the proceedings to end to escort the patient back.

I suggest that tribunals should expect the responsible medical officer to request an informed nursing presence at the hearing, unless serious staffing problems prevent it. In any proposed changes to tribunal procedure, this should be incorporated formally into the proceedings.

Wood, J. (1998) What I expect of my psychiatrist: the mental health review tribunal. Advances in Psychiatric Treatment, 4, 197-201.

Philip Seager Tribunal Member Trent Region, 9 Blacka Moor Road, Dore, Sheffield S17 3GH

\section{Literature on puerperal disorders}

Sir: How can Ian Brockington (1998) write a review on puerperal disorders with only two references to work published after 1988 (one of them his own)? What about the work of Lynne Murray and associates (including Peter Cooper, who gets a 1987 mention; see Murray \& Cooper, 1997a, b for example). This is not up-to-date.

Brockington, I. (1998) Puerperal disorders. Advances in Psychiatric Treatment, 4, $312-319$.

Murray, L. \& Cooper, P. (eds) (1997a) Postpartum Depression and Child Development. New York: Guilford Press.
- \& - (1997b) Postpartum Depression and Child Development Psychological Medicine, 27, 253-260.

Sebastian Kraemer Consultant Child and Adolescent Psychiatrist, Tavistock and Portman NHS Trust, 120 Belsize Lane, London NW3 5BA

Author's reply: The answer to Kraemer's question is that I was asked to write an article on Puerperal Disorders - Treatment of Mothers about 4000 words long, with 20-30 references. Under such a restriction, it seemed best to reference pioneering works - those whose ideas, observations and exemplary investigations have shaped our present knowledge and practice (I cited my own work, Motherhood and Mental Health only because it is a source for 2650 other references). As an example of the choices I made, I admire Murray \& Carothers' (1990) validation of the Edinburgh Postnatal Depression Scale, but preferred to cite Cox's (1987) original publication of the questionnaire.

Murray and various American teams have conducted sophisticated studies of normal motherinfant interactions, but so far these have not helped with the management of severe 'bonding' disorders and rejection of the infant. I know the multi-author work cited by Kraemer: it includes excellent chapters by Papoušek on the infant's role in mother-child interaction, and by Field on interventions like infant massage and interaction coaching; but I had already included the points they make.

Recency for its own sake is a superficial index of scholarship; failure to cite recent articles does not mean that my advice to consultants is dated.

Cox, J. L., Holden, J. M. \& Sagovsky, R. (1987) Detection of postnatal depression: development of the 10-item Edinburgh Postnatal Scale. British Journal of Psychiatry, 150, 782-786.

Murray, L. \& Carothers, A. D. (1990) The validation of the Edinburgh Postnatal Depression Scale on a community sample. British Journal of Psychiatry, 157, 288-290.

Ian Brockington Head of Department, Department of Psychiatry, Division of Neuroscience, The University of Birmingham, Queen Elizabeth Psychiatric Hospital, Mindelsohn Way, Birmingham B15 2QZ 